\title{
Combined chemoradiation of cisplatin versus carboplatin in cervical carcinoma: a single institution experience from Thailand
}

\author{
Ekkasit Tharavichitkul ${ }^{1 *}$, Vicharn Lorvidhaya', Pimkhuan Kamnerdsupaphon', Vimol Sukthomya', \\ Somvilai Chakrabandhu', Pitchayaponne Klunklin', Wimrak Onchan', Bongkoch Supawongwattana', \\ Nantaka Pukanhaphan', Razvan Galalae ${ }^{2,3}$ and Imjai Chitapanarux ${ }^{1}$
}

\begin{abstract}
Background: To report the results of combined chemoradiation (CCRT) with cisplatin versus carboplatin in locally advanced cervical carcinoma.

Methods: From 2009 to 2013, 255 patients with stage IIB-IVA cervical carcinoma, according to FIGO staging were prospectively assigned to be treated with pelvic radiotherapy followed by brachytherapy given concurrently with cisplatin or carboplatin in the treatment of locally advanced cervical cancer. Treatment outcomes and toxicitiy were evaluated.

Results: Two-hundred and thirteen patients could be evaluated. At a median follow-up time of 43 months (6-69 months), the 3-year local control, disease-free survival, metastasis-free survival and overall survival rates were 93, 80.8, 85.0 and $87.3 \%$, respectively. No statistical difference in terms of local control, disease-free survival, metastasis-free survival and overall survival rates between cisplatin and carboplatin treatments was observed in this study. Eighty-six percents of the patients in the carboplatin group could receive more than 4 cycles, while there were only $72 \%$ in the cisplatin group who completed more than 4 cycles $(p=0.02)$. In terms of acute toxicity, cisplatin caused significantly more anemia $(p=0.026)$, neutropenia $(p=0.044)$ and nephrotoxicity $(p=0.031)$ than carboplatin. No difference in late toxicity was observed in this study.
\end{abstract}

Conclusion: Carboplatin yielded comparable results to cisplatin in concurrent chemo-radiation for locally advanced cervical cancer. In addition, carboplatin was associated with a better compliance rate and was associated with less of anemia, neutropenia and nephrotoxicity.

Keywords: Cervical carcinoma, Chemo-radiation, Cisplatin, Carboplatin

\section{Backgrounds}

Cervical carcinoma is one of the most frequent cancer entities in Northern Thailand. According to the report of Kamnerdsupaphon et al. the age-standardized incidence rate22.7 per 100,000 and there were 234 new cases of cervix cancer diagnosed in 2005 and was one of the three most common cancers in female. Moreover, it ranked second after breast cancer [1]. The treatment options of cervical cancer are composed of surgery,

\footnotetext{
*Correspondence: paan_31@hotmail.com

'The Division of Therapeutic Radiology and Oncology, Department of Radiology, Faculty of Medicine, Chiang Mai University, Chiang Mai, Thailand Full list of author information is available at the end of the article
}

radiotherapy and/or chemotherapy according to stage and performance status of patients. For locally advanced disease, pelvic radiation and brachytherapy given concurrently with a platinum-based regimen is the standard treatment [2-4].

Weekly cisplatin is the most commonly used regimen for chemoradiation. However, it may cause acute toxicities, including nephrotoxicity and ototoxicity [5]. The comparative data between cisplatin and carboplatin were generally assessed in metastatic disease and mostly in phase II or retrospective studies [6-8]. In locally advanced cervical cancer, no prospective study has compared outcomes and treatment related toxicities between the two 
types of chemotherapy. One retrospective study on cisplatin versus carboplatin for concurrent chemoradiation for locally advanced cervical cancer reported carboplatin did not showed benefits over cisplatin [9]. To our knowledge, there were many published studies that reported the experiences of concurrent carboplatin [10-15]. In our center, carboplatin has been used for patients with poor functional status or age $>70$ or any age with poor creatinine clearance. The question of using carboplatin in good performance status needs to be answered. We performed this observational study to evaluate prospectively the disease-related outcomes and therapy -related toxicity of cisplatin versus carboplatin in concurrent chemoradiation for patients with locally advanced cervical cancer.

\section{Methods}

\section{Patients}

Two-hundred and fifty five patients with biopsy proven cervical cancer were included in this study from February 2009 to February 2013. All enrolled cervical cancer patients were classified as IIB-IVA by FIGO clinical staging, were 18-70 years old at study entry and had a Karnofsky performance status $>70 \%$. All patients had normal laboratory results with hemoglobin $(\mathrm{Hb}) \geq 10 \mathrm{~g} / \mathrm{dl}$, white blood count (WBC) $\geq 3000$ cells $/ \mathrm{mm}^{3}$, platelet count $\geq 100,000$ cells/ $\mathrm{mm}^{3}$, serum creatinine clearance $\geq 50 \mathrm{ml} / \mathrm{min}$ and normal liver function tests.

Patients with a severe co-morbidity, pregnancy, previous radiotherapy, distant metastases at diagnosis or history of allergies were excluded from the study.

This study was approved by the Ethic committee of faculty of medicine, Chiang Mai University with the

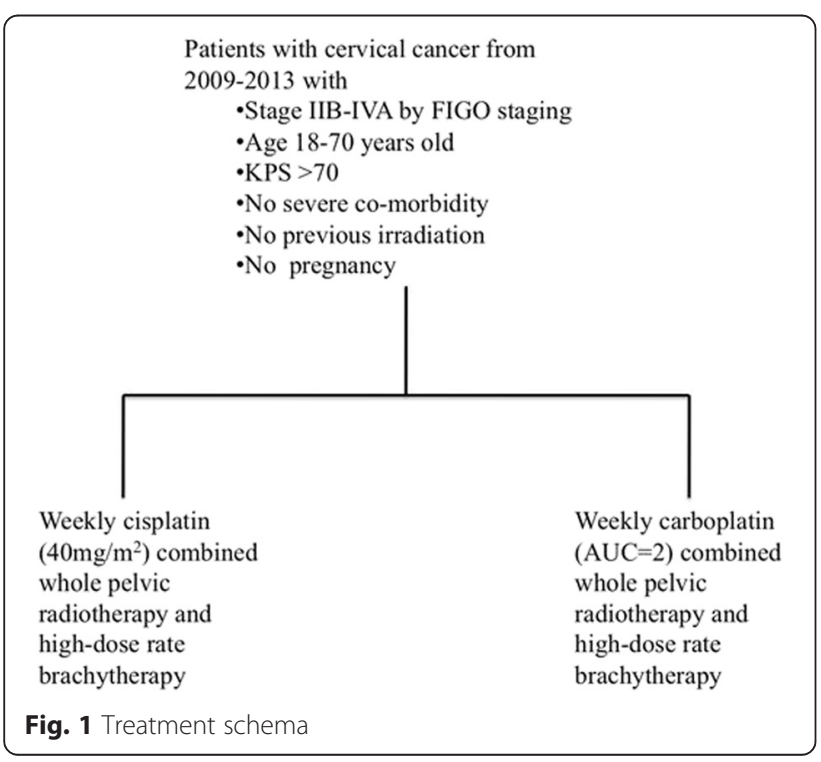

study code of RAD-08-12-12A-13. This study was performed in accordance with the principles of human clinical trials and the Helsinki Declaration (1975 edition and 2000 revised edition). All of the patients signed informed consent before treatment.

\section{Radiotherapy techniques}

Radiotherapy for cervical cancer in our institution is performed in concordance with the publication by Lorvidhaya et al. [16].

\section{Whole pelvic radiotherapy (WPRT)}

All patients received WPRT to the primary tumor and pelvic lymph nodes by conventional radiotherapy to the total dose of $50 \mathrm{~Gy}$ in 25 fractions. After $44 \mathrm{~Gy}$, central shielding was conventionally added to reduce the bladder and rectal dose. After $50 \mathrm{~Gy}$,

Table 1 Patient characteristics by study groups

\begin{tabular}{|c|c|c|c|}
\hline Parameters & cisplatin $(N=137)$ & carboplatin $(N=76)$ & $P$-value \\
\hline Age (years) & $51.6(21-67)$ & $53.8(35-70)$ & 0.051 \\
\hline $\begin{array}{l}\text { Maximal diameter of } \\
\text { primary tumor }(\mathrm{cm})\end{array}$ & $4.5(2-8)$ & $4.3(2-9)$ & 0.4 \\
\hline Stage & & & 0.09 \\
\hline$\| B$ & $91(66.4 \%)$ & $43(56.6 \%)$ & \\
\hline$\| \mathrm{A}$ & 0 & $2(2.6 \%)$ & \\
\hline IIIB & $44(32.1 \%)$ & $31(40.8 \%)$ & \\
\hline IVA & $2(1.5 \%)$ & 0 & \\
\hline Pelvic Lymph nodes & & & 0.63 \\
\hline No & $72(52.6 \%)$ & $45(59.2 \%)$ & \\
\hline Yes & $14(10.2 \%)$ & $6(7.9 \%)$ & \\
\hline Unknown & $51(37.2 \%)$ & 25(32.9\%) & \\
\hline Histology & & & 0.4 \\
\hline SCCA & $114(83.2 \%)$ & $66(86.8 \%)$ & \\
\hline ACA & $21(15.3 \%)$ & $9(11.8 \%)$ & \\
\hline Others & $2(1.5 \%)$ & $1(1.3 \%)$ & \\
\hline Histologic grade & & & 0.66 \\
\hline 1 & $18(14.8 \%)$ & $9(13.4 \%)$ & \\
\hline 2 & $78(63.9 \%)$ & 47(70.1\%) & \\
\hline 3 & $26(21.3 \%)$ & $11(16.4 \%)$ & \\
\hline Cycles & & & 0.02 \\
\hline Up to 4 cycles & $38(27.7 \%)$ & 10(13.2\%) & \\
\hline 5 to 6 cycles & $99(72.3 \%)$ & $66(86.8 \%)$ & \\
\hline $\begin{array}{l}\text { Total treatment } \\
\text { time (days) }\end{array}$ & $56.8(34-114)$ & $56(43-173)$ & 0.39 \\
\hline $\begin{array}{l}\text { Median follow-up } \\
\text { time (months) }\end{array}$ & $39.8(6-69)$ & $40.6(6-69)$ & 0.76 \\
\hline
\end{tabular}


Table 2 The 3-year local control, disease-free survival, metastasisfree survivaland overall survival rates of cisplatin versus carboplatin

\begin{tabular}{lllc}
\hline Parameters & Cisplatin $(N=137)$ & Carboplatin $(N=76)$ & $p$-value \\
\hline Local control & $94.9 \%$ & $89.5 \%$ & 0.13 \\
Disease-free survival & $81.8 \%$ & $78.9 \%$ & 0.62 \\
Metastasis-free & $83.9 \%$ & $86.8 \%$ & 0.56 \\
survival & & & \\
Overall survival & $86.1 \%$ & $89.5 \%$ & 0.48 \\
\hline
\end{tabular}

parametrial boost was performed to a cumulative dose of 56 Gy according to our institutional protocol.

\section{Intracavitary Brachytherapy (ICBT)}

ICBT was used in all patients. The tandem/ovoids (Fletcher-Williamson "Asia-Pacific" model) or tandem/cylinder (in case of more than one-third vaginal involvement) were used. Four applications were performed in all
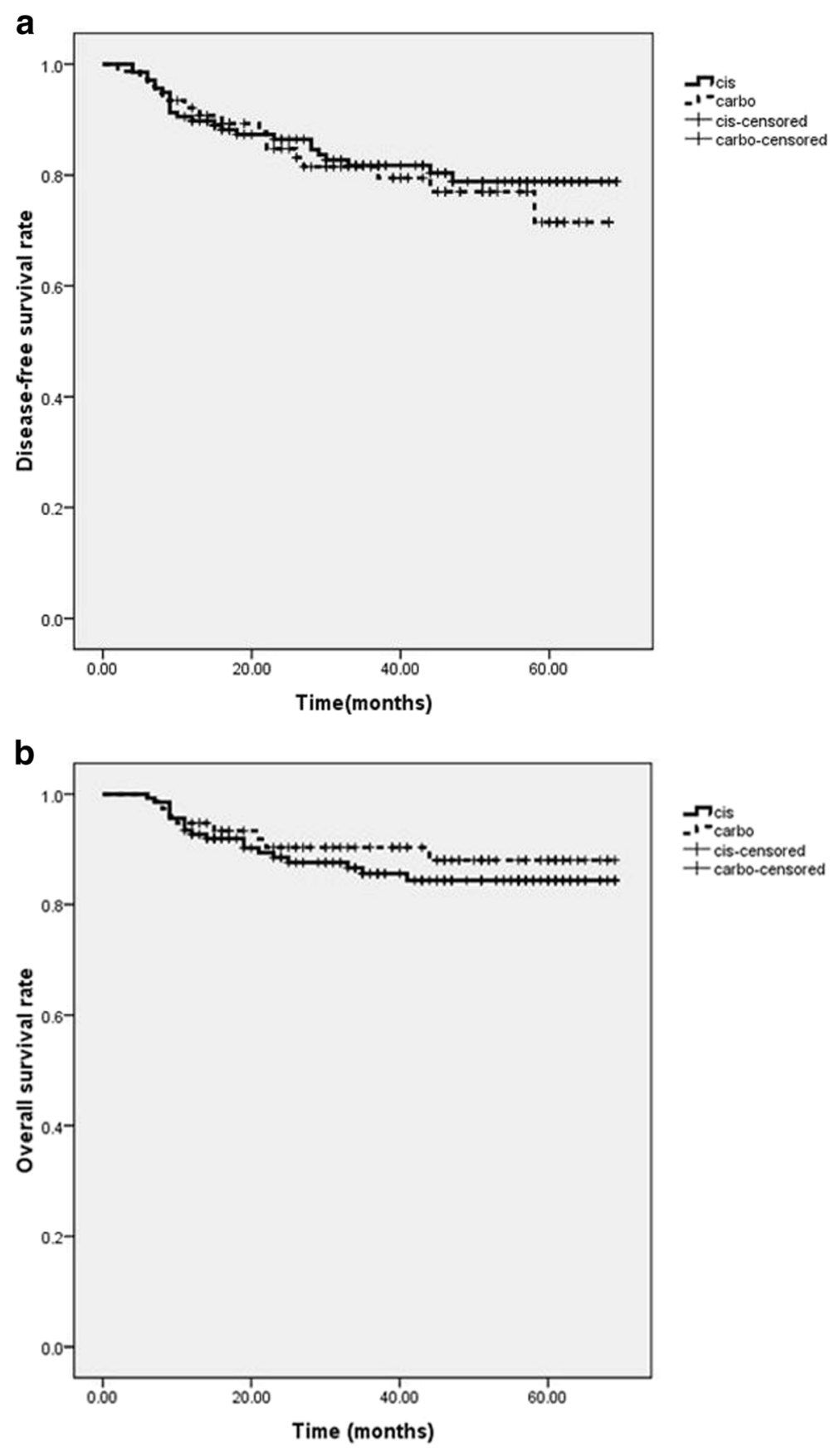

$\boldsymbol{T}$ cis

+ cis-censored

+ carbo-censored

Fig. 2 Kaplan-Meier curves showing (a) disease-free survival rate and (b) overall survival rates of cisplatin (continuous line) versus carboplatin (dotted line) 
patients. The first BT application was generally planned after the fourth week of WPRT with 1-2 fractions per week. The total dose of 24-28 Gy in 4 fractions was prescribed.

\section{Combined chemo-radiation (CCRT)}

All enrolled patients were assigned to receive cisplatin or carboplatin after study enrollment. CCRT with weekly cisplatin at a dose of $40 \mathrm{mg} / \mathrm{m}^{2}$ or weekly carboplatin at a dose of area under curve (AUC) equal to 2 for a maximum of six courses was given to all patients with sufficient kidney and bone marrow function during the EBRT. For the dosing of carboplatin, glomerular filtration rate (GFR) was calculated from serum creatinine, age and body weight and the dose of AUC 2 was calculated from the GFR by using Calvert's formula [17]. The maximum dose of chemotherapy for each cycle was $70 \mathrm{mg}$ of cisplatin and $200 \mathrm{mg}$ of carboplatin. Complete blood counts and renal function tests (serum blood urea nitrogen and creatinine) were evaluated weekly before consideration of chemotherapy. The dose of chemotherapy was modified according to a weekly assessment of creatinine clearance prior to each applied dose. Chemotherapy was interrupted when creatinine clearance was less than $40 \mathrm{ml} / \mathrm{min}$ for cisplatin and it was stopped when creatinine clearance was less than $30 \mathrm{ng} / \mathrm{ml}$ (Fig. 1).

\section{Study end point}

The primary end point was overall survival rate. Other treatment results and toxicies were evacuate as secondary end point. All events were measured from the date of randomization to the date of their occurrence or the the date of the last follow-up visit. Toxicity were graded according to the Common Terminology Criterias of Adverse Events (CTCAE) version 3.0 [18].

\section{Follow-up program}

After treatment was completed, patients were appointed to visits including vaginal examination (PV exam) in a follow-up program. The follow-up schedule included visits every 3-4 months in the first 2 years after treatment, every 6 months in the $3^{\text {rd }}$ to $5^{\text {th }}$ year and then annually after the $5^{\text {th }}$ year. A vaginal examination was performed to evaluate the disease status according to the World Health Organization (WHO) criteria [19]. Further investigations to identify disease progression were performed when indicated by clinical findings. Late toxicities were evaluated according to the Radiation Therapy Oncology Group/European Organization of Research and Treatment of Cancer (RTOG/EORTC) late toxicity criteria [20]. CTCAE version 3.0 was only used to evaluate vaginal obstruction.

\section{Statistical analysis}

Study enrollment was planned for 5 years and performed from 2009-2013. Overall survival (OS), metastasis-free survival (MFS), disease-free survival (DFS) and local control (LC) rates were evaluated using Kaplan-Meier estimates and compared using the log-rank test. Clinical and patient factors were compared using Pearson's chisquared, Mann-Whitney-U or Independent-Samples $T$ test as appropriate. All statistical analyses were performed using the SPSS version 17.00 (IBM company software, Chicago, Illinois, USA).

\section{Results}

\section{Patient characteristics}

Forty-two patients were excluded from analysis process due to incomplete treatment schedule (31 patients) and addition of neoadjuvnat chemotherapy (11 patients). Thus, 213 patients could be evaluated. One hundred thirty seven patients received weekly cisplatin and 76 patients weekly carboplatin. In the whole group, the mean age was 52.4 years (21-70 years). The mean maximal diameter of primary lesion was $4.4 \mathrm{~cm}(2-9 \mathrm{~cm})$. Stage IIB was the most common in patients (134 patients). 180 patients $(84.5 \%)$ had squamous cell carcinoma (SCCA) and the most common grade was moderately differentiated (58.7\%). The median follow-up time was 43 months (6-69 months) and the mean total treatment time was 56.5 days (34-173 days). All patient characteristics were shown in Table 1.

\section{Treatment results}

The 3-year local control, disease-free survival, metastasisfree survival and overall survival rates were $93 \%, 80.8,85$ and $87.3 \%$, respectively. 33 patients (15.5\%) developed distant metastasis and 18 patients $(8.4 \%)$ developed lymph

Table 3 The 3- year local control rate, disease-free survival rate, metastasis-free survival and overall survival rate of cisplatin versus carboplatin according to stage

\begin{tabular}{llll}
\hline Stage IIB & Cisplatin $(N=137)$ & Carboplatin $(N=76)$ & $p$-value \\
Local control & $96.7 \%$ & $95.3 \%$ & 0.68 \\
Disease-free survival & $86.8 \%$ & $86 \%$ & 0.78 \\
$\begin{array}{l}\text { Metastasis-free } \\
\text { survival }\end{array}$ & $87.9 \%$ & $88.4 \%$ & 0.98 \\
Overall survival & $89 \%$ & $93 \%$ & 0.5 \\
Stage IIIB & Cisplatin $(N=137)$ & Carboplatin $(N=76)$ & $p$-value \\
Local control & $93.2 \%$ & $83.9 \%$ & 0.22 \\
Disease-free survival & $75 \%$ & $71 \%$ & 0.88 \\
Metastasis-free & $77.3 \%$ & $83.9 \%$ & 0.44 \\
survival & & $84 \%$ & 0.99 \\
Overall survival & $84.1 \%$ & & \\
\hline
\end{tabular}



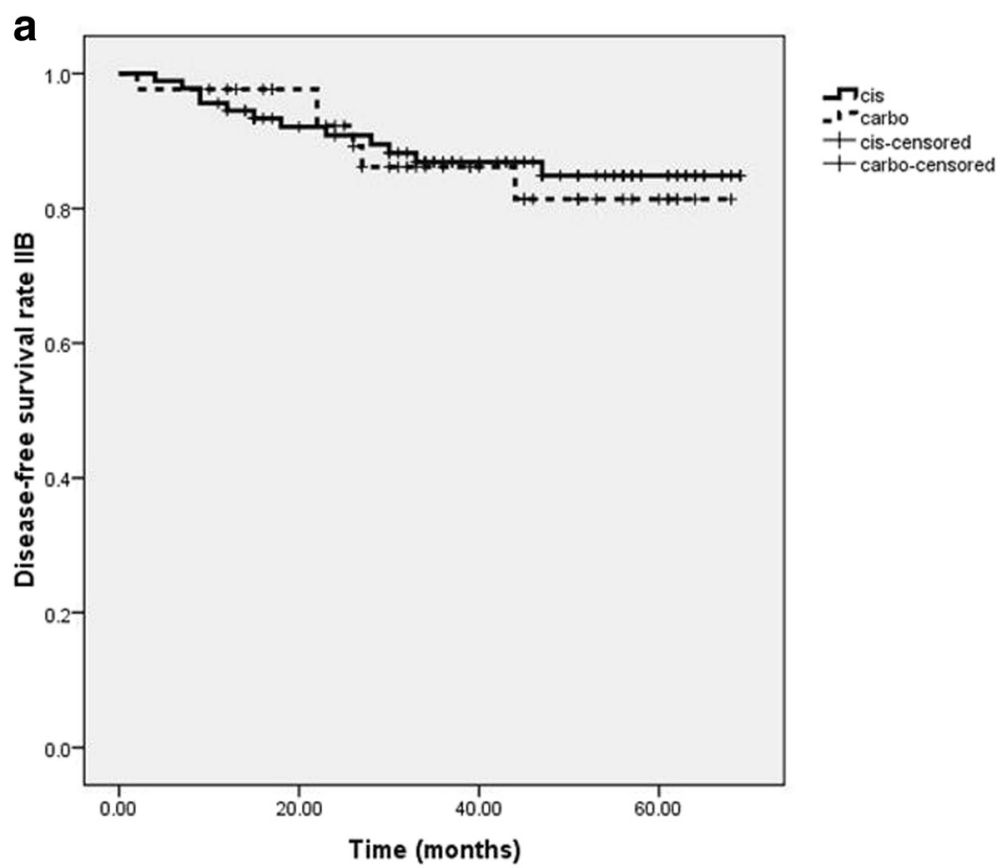

b

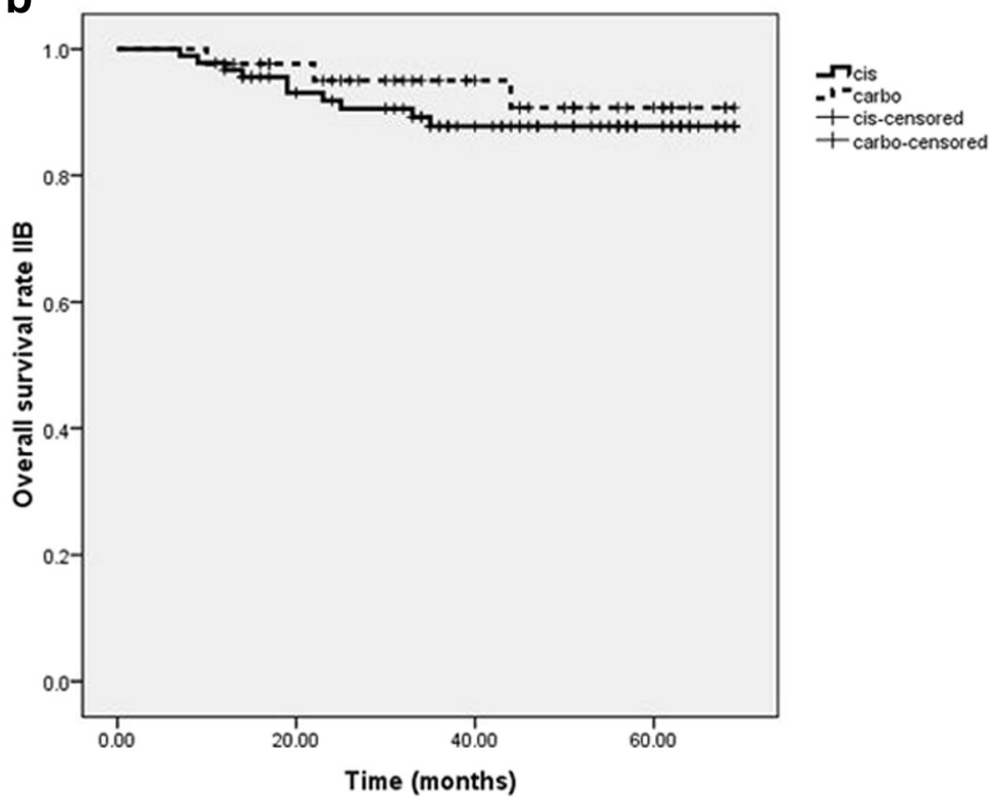

Fig. 3 Kaplan-Meier curves showing (a) disease-free survival rate and (b) overall survival rates of cisplatin (continuous line) versus carboplatin (dotted line) in stage IIB of cervical carcinoma

node metastases. No statistical significance in terms of local control, disease-free survival, metastasis-free survival and overall survival rates was observed between the cisplatin and carboplatin cohorts. All data are detailed in Table 2 and Fig. 2.

Analyses were performed by stratification on stage IIB (135 patients) and stage IIIB (74 patients) which composed the largest populations in these groups. In stage IIB, the local control, disease-free survival, metastasis- free survival and overall survival rates were 96.3, 86.6, 88.1 , and $90.3 \%$, respectively. In stage IIIB, the local control, disease-free survival, metastasis-free survival and overall survival rates were 89.3, 73.3, 80 and $84 \%$, respectively. No statistically significant difference between both study groups in terms of local control, disease-free survival and overall survival rates could be identified stratified by stage. All data of stage IIB and IIIB are shown in Table 3 and Figs. 3 and 4. 
a
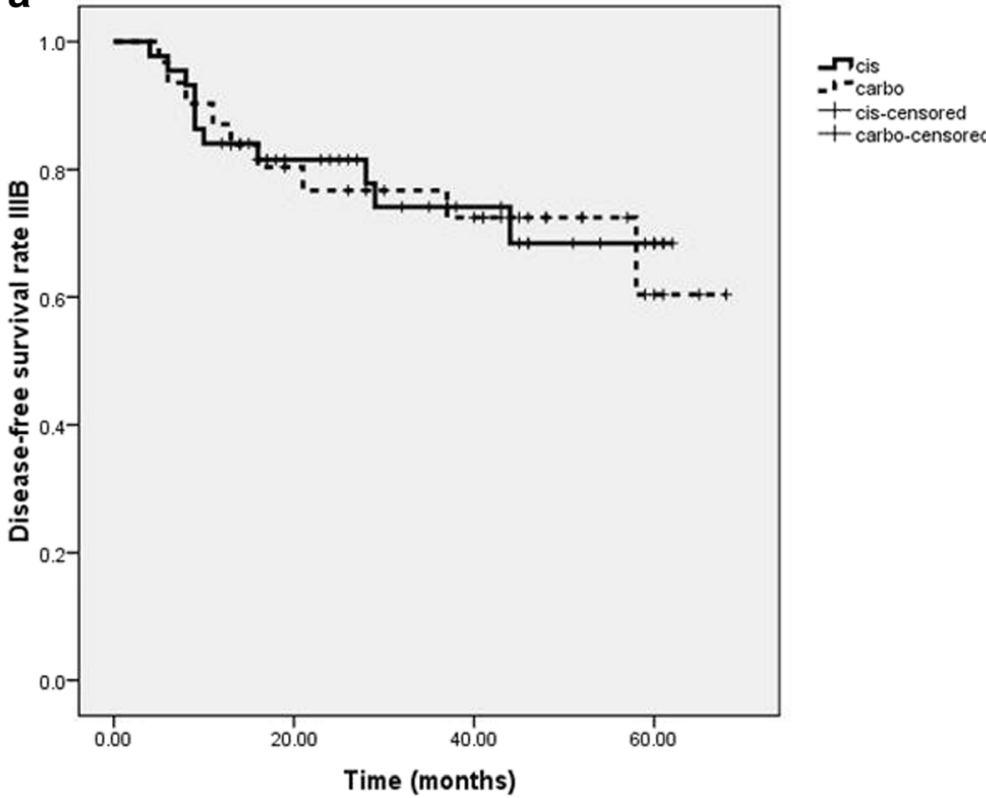

b

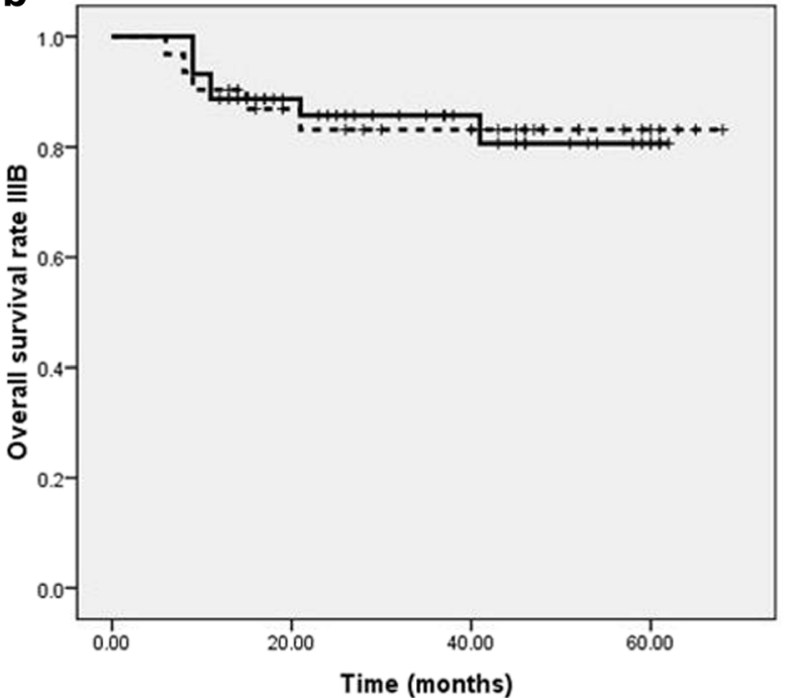

$\boldsymbol{- 1}$ cis

+ cis-censored

+ carbo-censored

Fig. 4 Kaplan-Meier curves showing (a) disease-free survival rate and (b)

b) overall survival rates of cisplatin (continuous line) versus carboplatin (dotted line) in stage IIIB of cervical carcinoma

\section{Toxicity profiles}

The most common toxicities were anemia (18.8\% or 40 patients) for acute toxicity and gastrointestinal side effects (14.6\% or 31 patients) for late toxicity. In terms of acute toxicity, patients who received cisplatin developed higher rates of anemia, neutropenia and renal toxicity than the patients in the carboplatin group. No difference in thrombocytopenia, radiation dermatitis, proctitis or cystitis was observed. All data of acute toxicity are shown in Table 4.
In terms of late toxicity, no statistically significant difference between the cisplatin and carboplatin groups for gastrointestinal, genitourinary, dermatological or vaginal toxicity was found. All data of late toxicity stratified by study group are shown in Table 5.

\section{Discussion}

The present study reports outcomes following CCRT using carboplatin in comparison to cisplatin for locally advanced carcinoma of cervix uteri in good general 
Table 4 Acute toxicity of cisplatin versus carboplatin

\begin{tabular}{|c|c|c|c|}
\hline Acute toxicity & cisplatin $(N=137)$ & carboplatin $(N=76)$ & $P$-value \\
\hline Anemia & & & 0.026 \\
\hline Grade 0 & $87(63.5 \%)$ & $57(75.0 \%)$ & \\
\hline Grade 1 & 19(13.9\%) & $10(13.2 \%)$ & \\
\hline Grade 2 & $28(20.7 \%)$ & $5(6.6 \%)$ & \\
\hline Grade 3 & $3(2.2 \%)$ & $4(5.3 \%)$ & \\
\hline Neutropenia & & & 0.044 \\
\hline Grade 0 & $84(61.3 \%)$ & $57(75 \%)$ & \\
\hline Grade 1 & $25(18.2 \%)$ & $14(18.4 \%)$ & \\
\hline Grade 2 & $25(18.2 \%)$ & $5(6.6 \%)$ & \\
\hline Grade 3 & $3(2.2 \%)$ & 0 & \\
\hline Thrombocytopenia & & & 0.392 \\
\hline Grade 0 & 128(93.4 \%) & $72(94.7 \%)$ & \\
\hline Grade 1 & $4(2.9 \%)$ & 0 & \\
\hline Grade 2 & $4(2.9 \%)$ & $4(5.3 \%)$ & \\
\hline Grade 3 & $1(0.7 \%)$ & 0 & \\
\hline Renal toxicity & & & 0.031 \\
\hline Grade 0 & $112(81.8 \%)$ & 73(96.5 \%) & \\
\hline Grade 1 & $8(5.8 \%)$ & $1(1.3 \%)$ & \\
\hline Grade 2 & 10(7.3\%) & $1(1.3 \%)$ & \\
\hline Grade 3 & 7(5.1\%) & $1(1.3 \%)$ & \\
\hline Skin toxicity & & & 0.45 \\
\hline Grade 0 & 139(94.9\%) & 75(98.7\%) & \\
\hline Grade 1 & $4(2.9 \%)$ & $1(1.3 \%)$ & \\
\hline Grade 2 & $3(2.2 \%)$ & 0 & \\
\hline Proctitis & & & 0.94 \\
\hline Grade 0 & $122(89.1 \%)$ & $67(88.2 \%)$ & \\
\hline Grade 1 & $9(6.6 \%)$ & $6(7.9 \%)$ & \\
\hline Grade 2 & $6(4.4 \%)$ & $3(3.9 \%)$ & \\
\hline Cystitis & & & 0.066 \\
\hline Grade 0 & 130(94.9\%) & $67(88.2 \%)$ & \\
\hline Grade 1 & 7(5.1\%) & 7(9.2 \%) & \\
\hline Grade 2 & 0 & $2(2.6 \%)$ & \\
\hline
\end{tabular}

condition. Our data show comparable results of carboplatin versus cisplatin in CCRT in terms of local control, disease-free survival, metastasis-free survival and overall survival rates with $p$-value of $0.13,0.62,0.56$ and 0.48 , respectively. The present results are in concordance with the studies of Nam et al. and Au-Yeung et al. in terms of survival rates $[9,21]$. In stage IIB, local control, diseasefree survival, metastasis-free survival and overall survival rates between group I and group II were not statistically significant. In stage IIIB, no statistical significance in all endpoints could be observed as well.

In addition, the patient characteristics of both groups were well balanced without statistically significant
Table 5 Late toxicity profiles of cisplatin versus carboplatin

\begin{tabular}{|c|c|c|c|}
\hline Late toxicity & cisplatin $(N=137)$ & carboplatin $(N=76)$ & $p$-value \\
\hline Chronic Gl & & & 0.331 \\
\hline Grade 0 & 103(75.2\%) & $63(82.9 \%)$ & \\
\hline Grade 1 & $13(9.5 \%)$ & $3(3.9 \%)$ & \\
\hline Grade 2 & $15(10.9 \%)$ & $5(6.6 \%)$ & \\
\hline Grade 3 & $2(1.5 \%)$ & $3(3.9 \%)$ & \\
\hline Grade 4 & $4(2.9 \%)$ & $2(2.6 \%)$ & \\
\hline Chronic GU & & & 0.206 \\
\hline Grade 0 & $122(89.1 \%)$ & $69(90.8 \%)$ & \\
\hline Grade 1 & $6(4.4 \%)$ & $1(1.3 \%)$ & \\
\hline Grade 2 & $6(4.4 \%)$ & $1(1.3 \%)$ & \\
\hline Grade 3 & $1(0.7 \%)$ & $3(3.9 \%)$ & \\
\hline Grade 4 & $2(1.5 \%)$ & $2(2.6 \%)$ & \\
\hline Chronic skin & & & 1.00 \\
\hline Grade 0 & 135(98.5 \%) & 75(98.7\%) & \\
\hline Grade 1 & $1(0.7 \%)$ & 0 & \\
\hline Grade 2 & $1(0.7 \%)$ & $1(1.3 \%)$ & \\
\hline Subcutaneous tissue & & & 0.849 \\
\hline Grade 0 & $117(85.4 \%)$ & $65(85.5 \%)$ & \\
\hline Grade 1 & 13(9.5 \%) & $6(7.9 \%)$ & \\
\hline Grade 2 & $7(5.1 \%)$ & $5(6.6 \%)$ & \\
\hline Vaginal obstruction & & & 0.281 \\
\hline Grade 0 & $101(73.7 \%)$ & $58(76.3 \%)$ & \\
\hline Grade 1 & $17(12.4 \%)$ & $9(11.8 \%)$ & \\
\hline Grade 2 & 18(13.1\%) & $6(7.9 \%)$ & \\
\hline Grade 3 & $1(0.7 \%)$ & $3(3.9 \%)$ & \\
\hline
\end{tabular}

differences in age, stage, maximal diameter, grade, histology, follow-up time and total treatment time although the mean age of group II (carboplatin) was slightly higher than group I (cisplatin) (53.8 years vs. 51.6 years; $p=0.051$ ). Group II patients had a higher compliance rate (received $>4$ cycles) than group I ( $86.8 \%$ vs. $72.3 \%$; $p=0.02$ ) and this finding matched the results of Nam et al. who showed that the numbers of received cycles of carboRT was higher than cisRT $(7.5$ versus $6 ; p<0.001)$ [21]. The main difference which was found in the present study is the acute toxicity. Cisplatin significantly caused more anemia $(p=0.026)$, neutropenia $(p=0.044)$ and nephrotoxicity $(p=0.031)$ than carboplatin while other parameters were equal. However, no statistical significance between the two groups in terms of late dermatotoxicities, gastrointestinal toxicities, genitourinary toxicities and vaginal toxicities were observed.

Carboplatin, either in combination or as a single-agent, may offer advantages in patients aged $>75$ years and in 
Table 6 Studies of carboplatin in CCRT for locally advanced cervical cancer

\begin{tabular}{|c|c|c|c|c|}
\hline Studies & $\mathrm{N}$ & Stage & Treatment results & Late Toxicities \\
\hline \multirow[t]{6}{*}{ Cetina et al. [11] } & \multirow{6}{*}{$\begin{array}{l}85 \text { (high risk of poor } \\
\text { renal dysfunction) }\end{array}$} & IB2 $4.7 \%$ & \multirow[t]{6}{*}{ OS $81 \%$} & \multirow[t]{6}{*}{-} \\
\hline & & ॥A $8.2 \%$ & & \\
\hline & & IIB $41.1 \%$ & & \\
\hline & & IIIA $4.7 \%$ & & \\
\hline & & IIIB $38.8 \%$ & & \\
\hline & & IVA $2.5 \%$ & & \\
\hline \multirow[t]{5}{*}{ Cetina et al. [12] } & \multirow[t]{5}{*}{59 (elderly patients) } & IB2 $8.4 \%$ & \multirow[t]{5}{*}{ 30-months OS $63 \%$} & \multirow[t]{5}{*}{-} \\
\hline & & IIA $13.5 \%$ & & \\
\hline & & IIB $52.5 \%$ & & \\
\hline & & IIIA $3.3 \%$ & & \\
\hline & & IIIB $18.6 \%$ & & \\
\hline \multirow[t]{4}{*}{ Katanyoo et al. [13] } & \multirow[t]{4}{*}{148} & IIB $50.7 \%$ & 2-years PFS $75.1 \%$ & Grade $3-4$ Gl $10.1 \%$ \\
\hline & & IIIB $48.0 \%$ & 5-years PFS $63 \%$ & \multirow[t]{3}{*}{ Grade 3-4 GU $0.7 \%$} \\
\hline & & IVA $1.3 \%$ & 2-years OS $81.9 \%$ & \\
\hline & & & 5-years OS $63.5 \%$ & \\
\hline \multirow[t]{3}{*}{ Sangkittipaiboon et al. [14] } & \multirow[t]{3}{*}{105} & IIB 83 & 5-years DFS 52.38 \% & Grade 3-4 Gl $3.2 \%$ \\
\hline & & III, 19 & \multirow[t]{2}{*}{ 5-years OS $56.19 \%$} & \multirow[t]{2}{*}{ Grade 3-4 GU 0 \% } \\
\hline & & IVA 3 & & \\
\hline \multirow[t]{3}{*}{ Our study } & \multirow[t]{3}{*}{76} & IIB $56.6 \%$ & 3-years DFS 78.9 \% & Grade 3-4 Gl 6.5 \% \\
\hline & & IIIA $2.6 \%$ & \multirow[t]{2}{*}{ 3-years OS $89.5 \%$} & \multirow[t]{2}{*}{ Grade 3-4 GU $6.5 \%$} \\
\hline & & IIIB $40.8 \%$ & & \\
\hline
\end{tabular}

Note: PFS progression-free survival, DFS Disease-free survival, OS overall survival, Gl gastrointestinal, GU genitourinary

those with decreased performance status [22]. Many studies reported the use of weekly carboplatin in combination with WPRT in the treatment of locally advanced cervical cancer. When we compared the carboplatin group with other studies, it showed comparable results (Table 6).

This study has some limitations. Firstly, this study is observational study. This study was firstly designed as non-inferiority study. The sample size for this study is determined to compare the 5-year survival rate and at least 223 patients in each arm were required to provide at least $80 \%$ power to be able to detect this difference in 5 -year survival rate between the study arms for a two-sided test with alpha $=0.05$. Unfortunately, the enrollment has problem due to poor accrual. Secondly, 42 patients had to be excluded from analysis. Eleven patients received neo-adjuvant chemotherapy and 31 patients had incomplete treatment.

Despite the mentioned limitations, this study showed similar results in terms of local control, disease-free survival, metastasis-free survival and overall survival rate in both study arms along with a better compliance rate and lower acute toxicity in terms of neutropenia and nephrotoxicity in the carboplatin cohort. This study results support the use of carboplatin in CCRT for locally advanced carcinoma of cervix uteri in patients with good general conditions. Moreover, the administration of carboplatin is generally easier than cisplatin. In our routine practice, the whole chemotherapy process per cycle lasts three hours for carboplatin versus six hours for cisplatin. In the context of a high-volume, high-workload institute, carboplatin-based CCRT is easier to manage.

\section{Conclusions}

The use of carboplatin in combination with radiation therapy is comparable to cisplatin in terms of treatment outcomes. In addition, the compliance in the carboplatin arm was better and the observed acute toxicity in terms of anemia, neutropenia and neprotoxicity was lower in the carboplatin versus cisplatin group. The present study results encourage the use of carboplatin in the treatment of locally advanced cervix carcinoma in patients with good general condition.

\section{Abbreviations}

ACA, adenocarcinoma; AUC, area under curve; CCRT, combined chemoradiation; CTCAE, common terminology criterias of adverse events; DFS, disease-free survival; FIGO, international federation of gynecology and obstetrics; GFR, glomerular filtration rate; Gl, gastrointestinal; GU, genitourinary; ICBT, intracavitary brachytherapy; OS, overall survival; PFS, progression-free survival; RTOG/EORTC, Radiation Therapy Oncology Group/European Organization of Research and 
Treatment of Cancer; SCCA, squamous cell carcinoma; WPRT, whole pelvic radiotherapy

\section{Acknowledgement}

The authors offers many thanks to all staffs the Division of Therapeutic Radiology and Oncology, Faculty of Medicine, Chiang Mai University for supporting this study.

\section{Funding}

This study was supported by the National Research University Project, under Thailand's Office of the Higher Education Commission and Faculty of Medicine, Chiang Mai University.

\section{Availability of data and materials}

The datasets supporting the conclusions of this article are included within the article.

\section{Authors' contributions}

ET, PK1, IC, VL, VS designed the study. ET, IC, SC, PK2, WO, BS, accrued and treated patients. ET, IC, SC, PK2, WO, BS collected data. ET, PK1 did literature research. NP analyzed data. ET interpreted data and wrote the manuscript. RG worked as manuscript consultant and proofreading. All authors approved the final report.

\section{Competing interests}

The authors declare that they have no competing interests.

\section{Consent for publication}

Not applicable.

\section{Ethics approval and consent to participate}

This study was performed in accordance with the principles of human clinical trials and the Helsinki Declaration (1975 edition and 2000 revised edition). This study was approved by the Ethics Committee of the Faculty of Medicine, Chiang Mai University with the study code of RAD-08-12-12A-13. All participants signed informed consent before participation.

\section{Author details}

'The Division of Therapeutic Radiology and Oncology, Department of Radiology, Faculty of Medicine, Chiang Mai University, Chiang Mai, Thailand. ${ }^{2}$ Faculty of Medicine, Christian-Albrechts-University, Kiel, Germany. ${ }^{3}$ Department of Radiooncology, Evangelical Clinics, Gelsenkirchen, Germany.

Received: 19 October 2015 Accepted: 13 July 2016

Published online: 19 July 2016

\section{References}

1. Kamnerdsupaphon P, Srisukho S, Sumitsawan Y, Lorvidhaya V, Sukthomya V. Cancers in Northern Thailand. Biomed Imaging Interv J. 2008:4:e46.

2. Rose PG, Bundy BN, Watkins EB, Thigpen JT, Deppe G, Maiman MA, et al. Concurrent cisplatin-based radiotherapy and chemotherapy for locally advanced cervical cancer. N Engl J Med. 1999;340:1144-53.

3. Keys HM, Bundy BN, Stehman FB, Muderspach LI, Chafe WE, Suggs 3rd CL, et al. Cisplatin, radiation, and adjuvant hysterectomy compared with radiation and adjuvant hysterectomy for bulky stage IB cervical carcinoma N Engl J Med. 1999;340:1154-61.

4. Eifel PJ, Winter K, Morris M, Levenback C, Grigsby PW, Cooper J, et al. Pelvic irradiation with concurrent chemotherapy versus pelvic and para-aortic irradiation for high-risk cervical cancer: an update of Radiation Therapy Oncology Group trial (RTOG) 90-01. J Clin Oncol. 2004;22:872-80.

5. Go RS, Adjei AA. Review of the comparative pharmacology and clinical activity of cisplatin and carboplatin. J Clin Oncol. 1999:17:409-22.

6. Tewari KS, Monk BJ. Gynecologic Oncology Group trials of chemotherapy for metastatic and recurrent cervical cancer. Curr Oncol Rep. 2005;7:419-34.

7. Tinkler AV, Bhagt K, Swenerton KD, et al. Carboplatin and paclitaxel for advanced and recurrent cervical carcinoma: the British Columbia Cancer Agency Experience. Gynecol Oncol. 2005;98:54-8.

8. Moore KN, Herzog TJ, Lewin S, et al. A comparison of cisplatin/paclitaxel and carboplatin/paclitaxel in stage IVB, recurrent or persistent cervical cancer. Gynecol Oncol. 2007;105:299-303.
9. Au-Yeung G, Mileshkin L, Bernshaw DM, Kondalsamy-Chennakesavan S, Rischin D, Narayan K. Radiation with cisplatin or carboplatin for locally advanced cervix cancer: the experience of a tertiary cancer centre. J Med Imaging Radiat Oncol. 2013:57(1):97-104.

10. Duenas-Gonzalez A, Cetina L, Sánchez B, Gomez E, Rivera L, Hinojosa J, et al. A phase I study of carboplatin concurrent with radiation in FIGO stage IIIB cervix uteri carcinoma. Int J Radiat Oncol Biol Phys. 2003;56(5):1361-5.

11. Cetina L, Garcia-Arias A, Uribe MJ, Astorga A, Candelaria M, Mota A, et al. Concurrent chemoradiation with carboplatin for locally advanced cervical cancer at high-risk for developing cisplatin-induced renal dysfunction. BMC Cancer. 2007:7 Suppl 1:A17.

12. Cetina L, Garcia-Arias A, Uribe Mde J, Candelaria M, Rivera L, Oñate-Ocaña L, et al. Concurrent chemoradiation with carboplatin for elderly, diabetic and hypertensive patients with locally advanced cervical cancer. Eur J Gynaecol Oncol. 2008;29(6):608-12.

13. Katanyoo K, Tangjitgamol S, Chongthanakorn M, et al. Treatment outcomes of concurrent weekly carboplatin with radiation therapy in locally advanced cervical cancer patients. Gynecol Oncol. 2011;123:571-6.

14. Sangkittipaiboon S. Long-term outcomes of concurrent chemoradiotherapy with weekly carboplatin in locally-advanced carcinoma of the uterine cervix patients. J Med Assoc Thai. 2014;97(1):12-9.

15. Veerasarn $V$, Lorvidhaya $V$, Kamnerdsupaphon $P$, et al. A randomized phase III trial of concurrent chemoradiotherapy in locally advanced cervical cancer: preliminary results. Gynecol Oncol. 2007:104:15-23.

16. Lorvidhaya $V$, Chitapanarux I, Sangruchi S, Lertsanguansinchai $P$, Kongthanarat $Y$, Tangkaratt $S$, et al. Concurrent mitomycin C, 5-fluorouracil, and radiotherapy in the treatment of locally advanced carcinoma of the cervix: a randomized trial. Int J Radiat Oncol Biol Phys. 2003;55(5):1226-32.

17. Calvert AH, Newell DR, Gumbrell LA, O'Reilly S, Burnell M, Boxall FE, et al. Car-boplatin dosage: prospective evaluation of a simple formula based on renal function. J Clin Oncol. 1989:7:1748-56.

18. National Cancer Institute. Common Terminology Criteria for Adverse Events (CTCAE). 2009, 2010

19. Miller $A B$, Hoogstraten $B$, Staquet $M$, Winkler $A$. Reporting results of cancer treatment. Cancer. 1981:47:207-14.

20. Cox JD, Stetz J, Pajak TF. Toxicity criteria of the Radiation Therapy Oncology Group (RTOG) and the European Organization for Research and Treatment of Cancer (EORTC). Int J Radiat Oncol Biol Phys. 1995;31:1341-6.

21. Nam EJ, Lee M, Yim GW, Kim JH, Kim S, Kim SW, et al. Comparison of carboplatin- and cisplatin-based concurrent chemoradiotherapy in locally advanced cervical cancer patients with morbidity risks. Oncologist. 2013;18(7):843-9.

22. Van Rijswijk RE, Vermorken JB. Drug therapy for gynaecological cancer in older women. Drugs Aging. 2000;17(1):13-32.

\section{Submit your next manuscript to BioMed Central and we will help you at every step:}

- We accept pre-submission inquiries

- Our selector tool helps you to find the most relevant journal

- We provide round the clock customer support

- Convenient online submission

- Thorough peer review

- Inclusion in PubMed and all major indexing services

- Maximum visibility for your research

Submit your manuscript at www.biomedcentral.com/submit
Biomed Central 